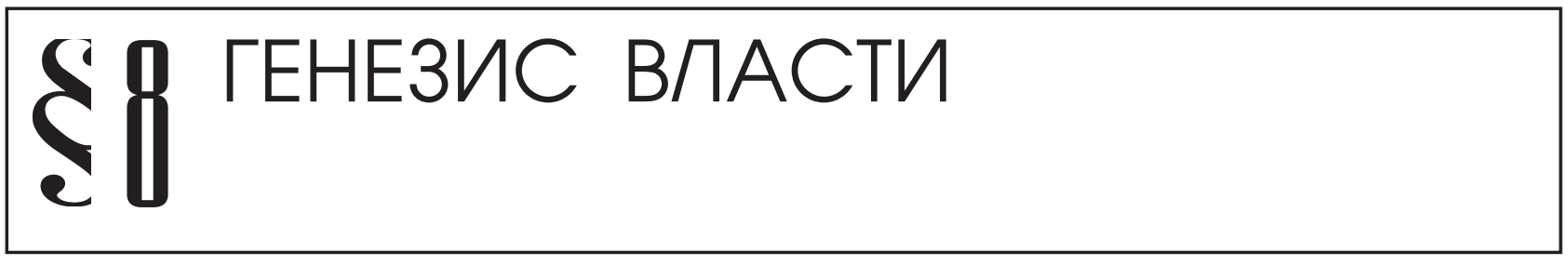

Горелова О.А.

\title{
ПРОБЛЕМЫ ПРИВЛЕЧЕНИЯ СУДЕЙ К ДИСЦИПЛИНАРНОЙ ОТВЕТСТВЕННОСТИ В СОВРЕМЕННОМ ЗАКОНОДАТЕЛЬСТВЕ И ПРАКТИКЕ КВАЛИФИКАЦИОННЫХ КОЛЛЕГИЙ СУДЕЙ
}

\begin{abstract}
Аннотация: $B$ статье рассмотрень понятие и виды дисииплинарной ответственности, наиболее актуальные проблемы, связанные с правовой регламентаиией дисииплинарной ответственности судей в рамках современного законодательства, отражен зарубежный опыт, регламентируюший виды дисииплинарной ответственности. Исследованы наиболее актуальные вопросы, возникающие в практике квалификационных коллегий судей при привлечении судей к ответственности, такэе рассмотрен зарубежный взгляд Международной комиссии юристов на современное состояние российского судейского сообщества и наиболее существенные замечания указанной комиссии по совершенствованию правовой системы, рассмотрень последние изменения в российском законодательстве. Отмечено мнение Совета судей Российской Федераиии, который высказался против внесения изменений указав, что существуютее правовое регулирование привлечения судей к дисииплинарной ответственности является достаточныл. По результатам исследования выявлены основные направления совериенствования российского законодательства, регулирующего дисииплинарную ответственность судей с учетом правоприменительной практики квалификаиионных коллегий судей: а именно предлагается конкретизировать основания привлечения судей к дисииплинарной ответственности, конкретизировать требования, касающиеся доказательств, допустимьх в рамках дисииплинарного производства, создать отдельные коллеги в составе Квалификаиионных коллегий судей, занимающихся рассмотрением лишь дел по вопросам привлечения судей к дисииплинарной ответственности.

Review: The article is devoted to the definition and description of forms of disciplinary liability as well as the most topical issues related to the legal regulation of disciplinary liability of judges by modern legislation. The author of the article analyzes the foreign experience in regulating forms of disciplinary liability to be applied. The author also studies the most nettlesome problems faced by the judges' qualifications boards when taking disciplinary actions against judges. The author also describes the opinion of the International Commission of Jurists on the actual status of the Russian community of judges and the most important remarks of the aforesaid Commission regarding the improvement of the legal system. In this regard the author also describes recent changes in the Russian legislation. The author also provides the opinion of the Judicial Council of the Russian Federation against making any alterations or changes in the legislation. According to the Judicial Council, the current legal regulation of taking disciplinary actions against judges is more than enough. Based on the results of the research, the author defines the main directions of improvement of the Russian legislation regulating disciplinary liability of judges taking into account the law-enforcement practice of the judges' qualifications boards. In particular, the author offers to specify the grounds for holding judges disciplinary liable, to specify requirements applied to evidence of a disciplinary offence and to create individual boards as the part of the Judges' Qualifications Boards that would examine only cases of taking disciplinary actions against judges.
\end{abstract}

Ключевые слова: Юриспруденция, судья, статус, независимость, дисииплинарная ответственность судей, квалификаиионные коллегии, дисииплинарное производство, проступок, взыскание, обязанности.

Keywords: legal studies, judge, status, independence, disciplinary liability, qualifications boards, disciplinary proceedings, act (behavior), punishment, responsibilities.

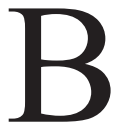

настоящее время дисциплинарная ответственность судей наступает при совершении дисциплинарного проступка. Согласно действующего законодательства, дисциплинарный проступок
- есть виновное действие (бездействие) при исполнении служебных обязанностей либо во внеслужебной деятельности, в результате которого были нарушены положения настоящего Закона и (или) кодекса 
судейской этики, утверждаемого Всероссийским съездом судей, что повлекло умаление авторитета судебной власти и причинение ущерба репутации судьи, на судью, за исключением судьи Конституционного Суда Российской Федерации, может быть наложено дисциплинарное взыскание в виде:

1) замечания;

2) предупреждения;

3 ) досрочного прекращения полномочий судьи ${ }^{1}$.

Конституционный суд Российской Федерации высказал свою позицию относительно необходимости и порядка привлечения судей к дисциплинарной ответственности. Так, по мнению Конституционного суда РФ, возможность привлечения судьи к дисциплинарной ответственности, имеющей существенную специфику, обусловленную специальным (конституционно-правовым) статусом судьи, обеспечивает баланс между независимостью судьи, которая сама по себе не предполагает бесконтрольности и безответственности, и его обязательствами перед обществом, что требует особой тщательности от законодателя при установлении оснований для применения к судье дисциплинарных санкций, а от органов, уполномоченных на их применение, - при определении наличия либо отсутствия таких оснований в каждом конкретном случае. Таким образом, исходя из конституционно-правового статуса судьи и природы осуществляемой им деятельности по отправлению правосудия, пункты 1 и 2 статьи 3 и пункт 1 статьи 12.1 Закона Российской Федерации «О статусе судей в Российской Федерации» в их системной взаимосвязи не предполагают привлечение судьи к дисциплинарной ответственности за судебную ошибку, если судья действовал в рамках судейского усмотрения и не допустил грубого нарушения при применении норм материального или процессуального права. Между тем, досрочное прекращение полномочий судьи как наиболее суровая мера дисциплинарной ответственности, влекущая значительные негативные последствия для судьи, который лишается всех гарантий, связанных со статусом судьи, включая полагающееся ему при удалении в отставку ежемесячное пожизненное содержание, может иметь место в тех случаях, когда исчерпаны все иные средства воз-

${ }^{1}$ См.: Закон Российской Федерации от 26 июня 1992 года N 3132-1 «О статусе судей в Российской Федерации» (с изм. От 02.07.2013г.) // Собрание законодательства Российской Федерации, 1995, N 26, ст. 2399; 2001, N 51, ст. 4834 , статья 12.1 . действия на судью, направленные на предупреждение дальнейших нарушений с его стороны, либо когда допущенное судьей нарушение подрывает доверие к судебной власти и не дает оснований рассчитывать на добросовестное и профессиональное выполнение им обязанностей судьи в будущем. Соответственно, такая санкция, как предупреждение, призванная оказывать дисциплинирующее воздействие на судью с целью сохранения баланса между ответственностью судей и их несменяемостью и обеспечения стабильности судейского корпуса, позволяет использовать досрочное прекращение полномочий судьи лишь в качестве исключительной меры воздействия. Таким образом, законодательство не предполагает привлечение судьи к дисциплинарной ответственности в виде досрочного прекращения полномочий судьи за сам факт принятия незаконного и необоснованного судебного акта, если оно обусловлено судебной ошибкой, явившейся следствием в том числе неверной оценки доказательств по делу либо неправильного применения нормы права, и если допущенные судьей нарушения закона не носят систематического характера, не обусловлены намеренным отступлением от общепризнанных морально-этических норм и не дискредитируют судебную власть. При этом незаконный характер судебного акта в любом случае должен быть установлен в надлежащем процессуальном порядке ${ }^{2}$.

Таким образом, современное законодательство не содержит конкретных составов дисциплинарных проступков, видов дисциплинарных санкций, а также основания привлечения судей к дисциплинарной ответственности. Предполагается, что нормативноправовые акты, регулирующие вопросы привлечения судей к дисциплинарной ответственности нуждаются в дополнении и уточнении. Поэтому еще в 2011 году был разработан законопроект, вносящий изменения в Закон «О статусе судей». Проектом федерального закона «О внесении изменений в статьи 121,14 и 15 Закона Российской Федерации «О статусе судей в Российской Федерации вводятся новые дисциплинарные взыскания в виде выговора и понижения квалифика-

\footnotetext{
${ }^{2}$ См.: Постановление Конституционного Суда Российской Федерации от 20 июля 2011 г. № 19-П, По делу о проверке конституционности положений пунктов 1 и 2 статьи 3 , пункта 1 статьи 8 и пункта 1 статьи 12.1 Закона Российской Федерации «О статусе судей в Российской Федерации» и статей 19, 21 и 22 Федерального закона «Об органах судейского сообщества в Российской Федерации» в связи с жалобой гражданки А.В. Матюшенко.
} 


\section{Политика и общество 2 (110) • 2014}

ционного класса судьи, что позволит применять более адекватное наказание. Законопроектом устанавливается, что дисциплинарное взыскание в виде досрочного прекращения полномочий или прекращение отставки судьи за совершение дисциплинарного проступка допускается только в случае совершения судьей грубого дисциплинарного проступка либо неоднократного (два и более в течение года) совершения дисциплинарных проступков. Законопроектом определяется содержание понятия «дисциплинарный проступок» в соответствии с Постановлением Пленума Верховного Суда Российской Федерации от 31 мая2007 г. № 27 «О практике рассмотрения судами дел об оспаривании решений квалификационных коллегий судей о привлечении судей судов общей юрисдикции к дисциплинарной ответственности», в котором под дисциплинарным проступком, влекущим дисциплинарное взыскание, следует понимать не только нарушение норм названного закона и положений кодекса судейской этики, но и нарушение общепринятых норм морали, обязанностей при отправлении правосудия, правил поведения при исполнении иных служебных обязанностей и во внеслужебной деятельности.

Тем не менее, Совет судей Российской Федерации высказался против внесения изменений указав, что существующее правовое регулирование привлечения судей к дисциплинарной ответственности является достаточным, в связи с чем отсутствует необходимость принятия специального закона в этой области. Более подробное законодательное регулирование вопросов, касающихся ответственности судей, может свести на нет важнейшую гарантию независимости судов, закрепленную в пункте 2 статьи 16 Закона Российской Федерации «О статусе судей в Российской Федерации», содержащую категорический запрет на привлечение судьи к какой-либо ответственности за выраженное при осуществлении правосудия мнение за исключением преступного умысла. Текучесть судейских кадров в немалой степени объясняется и постоянным риском быть подвергнутым дисциплинарной ответственности за выраженное при осуществлении правосудия мнении, что имеет место в действительности ${ }^{3}$.

21 июня 2013 года Государственной Думой Российской Федерации был принят Федеральный закон

\footnotetext{
${ }^{3}$ См.: Письмо Совета судей Российской Федерации в адрес Минюста России от 18 августа2011 г. № c/зак-424 // Электронный ресурс: http://files.sudrf.ru/2476/sud_community/ doc20111219-091828.doc
}

Российской Федерации от 2 июля 2013 г. N 179-Ф3 «О внесении изменений в Закон Российской Федерации «О статусе судей в Российской Федерации», одним из значимых нововведений стало расширенное понятие дисциплинарного проступка, а также появился срок давности привлечения судьи к дисциплинарной ответственности - решение о наложении на судью дисциплинарного взыскания теперь не может быть принято по истечении шести месяцев со дня выявления дисциплинарного проступка, за исключением периода временной нетрудоспособности судьи, нахождения его в отпуске и времени проведения служебной проверки, и по истечении двух лет со дня совершения дисциплинарного проступка.

Новое понятие дисциплинарного проступка было подвергнуто критике со стороны Международной комиссии юристов, включающая в себя 60 судей и юристов со всего мира. Ведущие мировые юристы считают, что данное определение является расплывчатым и не содержит предписания, на основании которого судья или иное лицо могли бы установить, какое именно поведение будет под него подпадать. Законопроект не содержит перечня конкретных видов проступков, но лишь указывает на общие признаки дисциплинарного проступка. В то время, как точность и предсказуемость оснований для привлечения к дисциплинарной ответственности является желательной для целей правовой определённости и особенно для защиты независимости судей; следовательно, необходимо предпринимать усилия, чтобы избежать расплывчатых оснований и широких определений.

Новая редакция закона не конкретизировала составы дисциплинарных проступков и основания привлечения судей к ответственности. В настоящее время, основания определяются следующим образом:

1. Дисциплинарное взыскание в виде замечания может налагаться на судью при малозначительности совершенного им дисциплинарного проступка, если квалификационная коллегия судей придет к выводу о возможности ограничиться устным порицанием действий (бездействия) судьи.

2. Дисциплинарное взыскание в виде предупреждения может налагаться на судью за совершение им дисциплинарного проступка, если квалификационная коллегия судей придет к выводу о невозможности применения к судье дисциплинарного взыскания в виде замечания или если судья ранее подвергался дисциплинарному взысканию. 
3. Дисциплинарное взыскание в виде досрочного прекращения полномочий судьи может налагаться на судью в исключительных случаях за существенное, виновное, несовместимое с высоким званием судьи нарушение положений настоящего Закона и (или) кодекса судейской этики, в том числе за нарушение указанных положений при осуществлении правосудия, если такое нарушение повлекло искажение принципов судопроизводства, грубое нарушение прав участников процесса, свидетельствует о невозможности продолжения осуществления судьей своих полномочий и установлено вступившим в законную силу судебным актом вышестоящей судебной инстанции или судебным актом, принятым по заявлению об ускорении рассмотрения дела либо о присуждении компенсации за нарушение права на судопроизводство в разумный срок ${ }^{4}$.

Международная комиссия юристов предлагает конкретизировать основания привлечения судей к ответственности в виде отсутствия беспристрастности, получения недозволенных указаний от должностных лиц, предвзятость, использования сведений, полученных из засекреченных источников, оказания влияния на другого судью, вмешательство в процесс принятия решения другим судьёй, раскрытия конфиденциальной информации, ненадлежащее отношение к сторонам по делу, недозволенное использование судейской должности в целях получения льгот или ухода от обязанности или ответственности, также расширить виды дисциплинаронго наказания в виде приостановление полномочий судьи, понижение квалификационного класса, перевод в другой суд или необходимость прохождения дополнительного обучения 5 .

Из зарубежного опыта, в Нидерландах существуют три вида взыскания: письменное предупреждение, временное отстранение от должности и увольнение. Во французском законодательстве предусмотрен более широкий спектр дисциплинарных взысканий для судей: выговор с занесением в личное дело, перевод на другую должность, отзыв определенных полномо-

${ }^{4}$ См.: Закон Российской Федерации от 26 июня 1992 года N 3132-1 «О статусе судей в Российской Федерации» (с изм. От 02.07.2013г.) // Собрание законодательства Российской Федерации, 1995, N 26, ст. 2399; 2001, N 51, ст. 4834, статья 12.1

${ }^{5}$ См.: Комментарий Международной комиссии юристов от 10.05.2013г. (г.Женева) Проект Закона о внесении изменений в Закон «О статусе судей» // Электронный ресурс: http:// www.president-sovet.ru чий, запрет рассматривать дела единолично на срок до 5 лет, понижение в ранге, временное отстранение от должности на срок до 1 года, с полной или частичной утратой зарплаты, перевод на нижеоплачиваемую должность, увольнение в отставку, с сохранением пенсии или с ее утратой, увольнение.

Многие эксперты считают, что в России достаточно большое количество судей привлекается в дисциплинарной ответственности и число уволенных судей также является высоким. Статистика показывает, что за последние 10 лет количество заявлений выросло более чем в 10 раз.

По данным Высшей Квалификационной коллегии Судей Российской Федерации если в первое четырехлетие (1993-1996 гг.) коллегия рассмотрела 300 заявлений и дала рекомендации 265 претендентам, то в самое интенсивное четырехлетие (2005-2008 гг.) рассмотрено 2482 заявления и рекомендованы 1682 претендента, то есть примерно по 100 заявлений и по 70 рекомендаций на каждом заседании. Рассмотрение обращений граждан и юридических лиц: 1800 - в первое четырехлетие и 39693 за 2009-2012 годы, то есть по 30 жалоб ежедневно. При этом, Высшая Квалификационная коллегия Судей Российской Федерации выделяет три главные причины: недостаточная мотивированность или отсутствие мотивировок принятых ККС решений, несоответствие выводов ККС обстоятельствам дела, нарушение процедуры рассмотрения. Отсутствие оснований для привлечения к дисциплинарной ответственности - характерная причина для отмены решений ККС. Если вывод в решении ККС о нарушении судьей Закона о статусе судей и Кодекса судейской этики сделан на основании недостоверных доказательств, к примеру, аудиозаписи, происхождение которой не проверено, или откровенно противоречивых показаниях свидетеля, то такое решение ККС естественным образом претендует на отмену. К примеру, в 2010 году Дисциплинарное судебное присутствие удовлетворило 34 процента жалоб на подобные решения ККС, в 2011 году - 42 процента, а в 2012 году 22 процента. Основными ошибками, повлекшими отмену решений квалификационных коллегий судей субъектов Российской Федерации, являлись по оценке самого ДСП следующие: нарушение процедуры привлечения судьи к дисциплинарной ответственности в виде досрочного прекращения полномочий; рассмотрение дисциплинарного дела в 


\section{Политика и общество 2 (110) • 2014}

отсутствие судьи при наличии сведений об уважительности причин, препятствовавших его явке на заседание квалификационной коллегии судей; ненадлежащее оформление документов, отражающих результаты голосования квалификационной коллегии судей; оставление без внимания всех данных, характеризующих судью и его профессиональную деятельность; оценка законности судебного акта, вступившего в законную силу; недоказанность факта совершения судьей дисциплинарного проступка ${ }^{6}$.

Дмитрий Анатольевич Медведев, будучи президентом Российской Федерации в феврале 2012 г. предлагал создать дисциплинарные коллегии судей субъектов Российской Федерации, которым передавались полномочия по рассмотрению дисциплинарных проступков судей от квалификационных коллегий судей. Иными словами, Дмитрий Медведев предлагал создать региональные Дисциплинарные Судебные присутствия $^{7}$. Эта идея была поддержана и председателем Конституционного суда Российской Федерации Валерием Дмитриевичем Зорькиным, который предложил распространить действующий механизм дисциплинарного судебного присутствия на субъекты федерации путем «формирования специальных квалификационных судов, которые, будучи судебными органами, приняли бы на себя существенную часть функций квалификационных коллегий судей прежде всего в части дисциплинарной ответственности» ${ }^{8}$.

Обобщая вышесказанное, можно сделать следующие выводы.

Вопрос привлечения судей к дисциплинарной ответственности является достаточно важным с точки зрения эффективности и правовой регламентации судебной системы России. Он содержит в себе такие разноплановые аспекты судебной реформы, как независимость судей, защита законных прав и свобод граждан, создание единого правового пространства страны, создание функционирующего правопорядка и укрепление управляемости в государстве. В рамках внесения

\footnotetext{
${ }^{6}$ См.: Доклад Председателя Высшей Квалификационной коллегии Судей Российской Федерации Тимошина Н.В. на семинаре-совещании с председателями квалификационных коллегий судей субъектов Российской Федерации (1921 июня 2013 г.) // Электронный ресурс: http://www.vkks.ru/

${ }^{7}$ См.: Медведев предлагает создать дисциплинарные коллегии для наказания судей, передав им полномочия ККС // Электронный ресурс: http://www.ks-ri.ru

${ }^{8}$ См.: Договориться о механизмах и мерах воздействия на судей не удалось // Электронный ресурс: http://www.zazakon.ru
}

последних изменений в Закон «О статусе судей» по состоянию на 02.07.2013г. необходимо отметить о существующих пробелах, устранение которых позволит конкретизировать саму процедуру привлечения к дисциплинарной ответственности и тем самым сократить возможное ущемление независимости судей.

На данный момент, так и не конкретизированы основания привлечения судей к дисциплинарной ответственности. Эти понятия немного размыты и существуют определенные трудности при разграничении действий судей, подпадающих под признаки дисциплинарного проступка, влекущего замечание, предупреждение и досрочное прекращение полномочий, от действий, не влекущих дисциплинарную ответственность. Так законодателю следовало уточнить понятие «малозначительности совершенного им дисциплинарного проступка».

С другой стороны, при существовании в России отдельного органа на федеральном уровне - Дисциплинарного Судебного присутствия, рассматривающим дела по жалобам на решения Высшей квалификационной коллегии судей Российской Федерации и квалификационных коллегий судей субъектов Российской Федерации о досрочном прекращении полномочий судей за совершение ими дисциплинарных проступков, следует предусмотреть в составе квалификационных коллегий судей субъектов РФ создание отдельных коллегий, занимающихся рассмотрением лишь дел по вопросам привлечения судей к дисциплинарной ответственности. Выделение такой профильно-направленной коллегии судей позволит усовершенствовать процедуру рассмотрения дел, и в частности о прекращении полномочий судьи.

Следует пересмотреть статью 22 Закона «Об органах судейского сообщества Российской Федерации» согласно которой, жалобы или сообщения, содержащие сведения о совершении судьей дисциплинарного проступка, поступившие от граждан, проверяются Квалификационной коллегий судей либо направляются для проверки председателю соответствующего суда. Предполагается, что такие проверки будут не всегда объективны, потому что председатель суда сам может вносить представления о привлечении судей к дисциплинарной ответственности. Что же касается проверок Квалификационными коллегиями судей закон не оговаривает качество проверки и не уточняет, какие именно аспекты подлежат проверке, какие доказательства могут быть исследованы. Согласно практике ВККС, большая часть жалоб возвращается заявителям, с указанием причины возвращения - «вопрос 
о возбуждении в отношении судьи уголовного дела решается на основании представления Генерального прокурора РФ, такого представления не поступало». Таким образом, коллегий судей возвращают жалобы даже не рассматривая доводы жалобы по существу.

В законодательстве отсутствуют требования, касающиеся доказательств, допустимых в рамках дисциплинарного производства. Неясно, какие доказательства считаются относимыми, допустимыми или достаточными и какие критерии используются для признания их таковыми. критерии используются для признания их таковыми.

\section{Библиография:}

1. Конституция Российской Федерации. [Электронный ресурс]: [(принята всенародным голосованием 12.12.1993) (с учетом поправок, внесенных ФКЗ о поправках к Конституции РФ от 30.12.2008 N 6-ФК3, от 30.12.2008 N 7-ФК3)]. // Российская газета. - 21.01.2009. - N 7.-Режим доступа: [Консультант плюс].-Загл. с экрана.

2. Федеральный конституционный закон от 9 ноября 2009 г. N 4-ФКЗ «О Дисциплинарном судебном присутствии» [Электронный ресурс]: [Федеральный закон от 09.11.2009 N 4-ФКЗ. // Российская газета. - 11.11.2009. - N 211. - Режим доступа: [Консультант плюс]. - Загл. с экрана.

3. Закон РФ от 26.06.1992 N 3132-1 (ред. от 08.12.2010) «О статусе судей в Российской Федерации» О статусе судей. [Электронный ресурс]: [Федеральный закон от 26.06.1992 N 3132-1 (ред. от 08.12.2011)]. // Российская газета.-29.07.1992. - N 170.-Режим доступа: [Консультант плюс]. Загл. с экрана.

4. ПостановлениеКонституционногоСудаРФот 18октября 2011 г. N 23-П «По делу о проверке конституционности положений статей 144, 145 и 448 Уголовно-процессуального кодекса Российской Федерации и пункта 8 статьи 16 Закона Российской Федерации «О статусе судей в Российской Федерации» в связи с жалобой гражданина С.Л. Панченко

5. Постановление Конституционного Суда Российской Федерации от 23 февраля 2008 г. N 3-П [Электронный ресурс] : [Постановление Конституционного Суда РФ от 23.02.2008 N 3-П По делу о проверке конституционности ряда положений статей 6.1 и 12.1 Закона Российской Федерации «О статусе судей в Российской Федера- ции» и статей 21, 22 и 26 Федерального закона «Об органах судейского сообщества в Российской Федерации» в связи с жалобами граждан Г.Н. Белюсовой, Г.И. Зиминой, Х.Б. Саркитова, С.В. Семак и А.А. Филатовой»]. // Российская газета. - 14.03.2008. - N 55. - Режим доступа: [Консультант плюс]. - Загл. с экрана.

6. Постановление Конституционного Суда Российской Федерации от 30 мая 2007 г. N 27 [Электронный ресурс] : [Постановление Пленума Верховного Суда РФ от 31.05.2007 N 27 (ред. от 20.05.2010) «О практике рассмотрения судами дел об оспаривании решений квалификационных коллегий судей о привлечении судей судов общей юрисдикции к дисциплинарной ответственности»]. // Российская газета.-08.06.2007. - N 122. - Режим доступа: [Консультант плюс]. - Загл. с экрана.

7. Постановление Конституционного Суда Российской Федерации от 20 июля 2011 г. N 19-П [Электронный pecypc] : [Постановление Конституционного Суда РФ от 20.07.2011 N 19-П «По делу о проверке конституционности положений пунктов 1 и 2 статьи 3 , пункта 1 статьи 8 и пункта 1 статьи 12.1 Закона Российской Федерации «О статусе судей в Российской Федерации» и статей 19, 21 и 22 Федерального закона «Об органах судейского сообщества в Российской Федерации» в связи с жалобой гражданки А.В. Матюшенко»]. // Российская газета.-03.08.2011. - N 168. - Режим доступа: [Консультант плюс]. - Загл. с экрана.

8. Договориться о механизмах и мерах воздействия на судей не удалось // Электронный ресурс: http:// www.zazakon.ru

9. Доклад Председателя Высшей Квалификационной коллегии Судей Российской Федерации Тимошина Н.В. на семинаре-совещании с председателями квалификационных коллегий судей субъектов Российской Федерации (19-21 июня 2013 г.) // Электронный ресурс: http:/www.vkks.ru/

10. Комментарий Международной комиссии юристов от 10.05.2013г. (г.Женева) Проект Закона о внесении изменений в Закон «О статусе судей» // Электронный ресурс: http:/www.president-sovet.ru

11. Медведев предлагает создать дисциплинарные коллегии для наказания судей, передав им полномочия ККС // Электронный ресурс: http://www.ks-ri.r

12. Письмо Совета судей Российской Федерации в адрес Минюста России от 18 августа2011 г. №c/ зак-424 // Электронный ресурс: http://files.sudrf. ru/2476/sud_community/doc20111219-091828.doc 


\section{Политика и общество 2 (110) 2014}

13. Ю. В. Щедрина Несменяемость судей в России во второй половине 60-Х-конце 80-х гг. XIX в.: законодательное закрепление и практика реализации // Право и политика.-2012.-9.-С. 1618-1627.

14. Бозров В.М. Независимость судьи и доктринально-правовое заключение ученого // Право и политика. - 2013. - 11. - С. 1508-1510. DOI: 10.7256/1811-9018.2013.11.10046.

15. Щедрина Ю.В. Социально-правовые гарантии независимости судей в России в 1860-х - 1890-х гг. // Право и политика. - 2014. - 2. - C. 207-218. DOI: 10.7256/1811-9018.2014.2.10892.

16. Коновалов А.О. Актуальные проблемы защиты нарушенного права на доступ к информации о деятельности судов в Российской Федерации // NB: Вопросы права и политики. - 2013. - 7. - С. 100124. DOI: 10.7256/2305-9699.2013.7.9008. URL: http://www.e-notabene.ru/lr/article_9008.html.

17. Е.Ю. Есева. Отвод судьи в гражданском процессе. Реальность или фикция?. // Право и политика. - 2013. - № 4. - C. 504-508. DOI: .10.7256/18119018.2013.04.8.

18. О.В. Брежнев. Неприкосновенность судей Конституционного суда России и конституционных (уставных) судов субъектов Российской Федерации: проблемы правового регулирования. // Право и политика. - 2010. - № 8

\section{References (transliteration):}

1. Yu. V. Shchedrina Nesmenyaemost' sudei v Rossii vo vtoroi polovine 60 -kh-kontse 80 -kh gg. XIX v.: zakonodatel'noe zakreplenie i praktika realizatsii // Pravo i politika.-2012.-9.-C. 1618-1627.

2. Bozrov V.M. Nezavisimost' sud'i i doktrinal'no-pravovoe zaklyuchenie uchenogo // Pravo i politika. 2013. - 11. - C. 1508-1510. DOI: 10.7256/18119018.2013.11.10046.

3. Shchedrina Yu.V. Sotsial'no-pravovye garantii nezavisimosti sudei v Rossii v 1860-kh - 1890-kh gg. // Pravo i politika. - 2014. - 2. - C. 207-218. DOI: 10.7256/1811-9018.2014.2.10892.

4. Konovalov A.O. Aktual'nye problemy zashchity narushennogo prava na dostup $\mathrm{k}$ informatsii o deyatel'nosti sudov v Rossiiskoi Federatsii // NB: Voprosy prava i politiki. - 2013. - 7. - C. 100-124. DOI: 10.7256/2305-9699.2013.7.9008. URL: http:// www.e-notabene.ru/lr/article_9008.html.

5. E.Yu. Eseva. Otvod sud'i v grazhdanskom protsesse. Real'nost' ili fiktsiya?. // Pravo i politika. - 2013. - № 4. - C. 504-508. DOI: .10.7256/1811-9018.2013.04.8.

6. O.V. Brezhnev. Neprikosnovennost' sudei Konstitutsionnogo suda Rossii i konstitutsionnykh (ustavnykh) sudov sub"'ektov Rossiiskoi Federatsii: problemy pravovogo regulirovaniya. // Pravo i politika. -2010 . - № 8 